\title{
LÍMITES Y POSIBILIDADES DE LOS ANÁLISIS LiDAR APLICADOS AL MEGALITISMO ASTURIANO. REVISIÓN DE CUATRO CONJUNTOS TUMULARES PREHISTÓRICOS EN EL CONCEJO DE SALAS (ESPAÑA)
}

\section{LIMITS AND POSSIBILITIES OF LiDAR ANALYSIS IN THE ASTURIAN MEGALITHISM. UPDATING THE INFORMATION OF FOUR MEGALITHIC NECROPOLISES OF SALAS COUNCIL (SPAIN)}

\author{
Fernando R. Del Cueto* \\ (Universidad de Oviedo) \\ Miguel Carrero Pazos \\ (UCL Institute of Archaeology)
}

\begin{abstract}
RESUMEN. El actual concejo de Salas (Asturias, España) agrupa un conjunto de unos 70 túmulos prehistóricos que están siendo objeto de análisis dentro del proyecto de La Cobertoria. El estudio implica la revisión de los datos disponibles en el inventario arqueológico, realizado en 1990, incorporando posicionamientos precisos, nuevas descripciones, así como el uso de LiDAR. Los principales datos recabados hasta el momento por el proyecto, mediante prospecciones de campo y remotas, se presentan en este trabajo. El proyecto ha englobado cuatro necrópolis diferentes, concentradas en dos sectores geográficos específicos del concejo, la zona noroccidental y la suroccidental. El análisis está aportando datos concretos acerca de cada estructura individual, su evolución y sus características, así como sobre las necrópolis, para así buscar una comprensión clara de su ubicación en el paisaje prehistórico.
\end{abstract}

PALABRAS CLAVE. Neolítico, Edad del Bronce, Arqueología del paisaje, prospecciones.

ABSTRACT. Around 70 prehistoric barrows are now under research in the current council of Salas (Asturias, Spain), as a part of the Cobertoria's Project. Focused on updating the archaeological data about the barrows included in the Sites and monument Record (1990), the research presented here adds new information about the structures; for instance, accurate GPS positions, new descriptions of the sites, as well as the data recovered after LiDAR analysis. The information presented in this paper was gathered combining field works with remote sensing techniques. Four different necropolises were analysed, focusing on two different areas of the council: northwestern and southwestern part. This research gives information about each barrow, its evolution and main features, as well as data about the necropolises in order to better understanding the prehistoric landscape.

KEYWORDS. Neolithic, Bronze Age, mounds, remote sensing, landscape archaeology, fieldwalking.

\footnotetext{
* Correspondencia a / Correspondence to: Fernando R. del Cueto, Universidad de Oviedo, Departamento de Historia, Facultad de Filosofía y Letras. Campus del Milán. Calle Amparo Pedregal, s/n (33011 Oviedo, Asturias) - rodriguezcfernando@uniovi.es - https://orcid.org/0000-0002-2721-7221.

Cómo citar / How to cite: R. del Cueto, Fernando; Carrero Pazos, Miguel (2021), "Límites y posibilidades de los análisis LiDAR aplicados al megalitismo asturiano. Revisión de cuatro conjuntos tumulares prehistóricos en el concejo de Salas (España)", Veleia, 38, 9-31. (https://doi.org/10.1387/ veleia.21455).
}

Recibido: 14 mayo 2020; aceptado: 5 agosto 2020.

ISSN 0213-2095 - elSSN 2444-3565 / (C) 2021 UPV/EHU 
1. Introducción. El proyecto de la Cobertoria (2015-2019)

El Proyecto de La Cobertoria tiene como objetivo principal el estudio arqueológico del conjunto de evidencias tumulares y megalíticas del concejo de Salas (Asturias). Para ello, y desde 2015, el proyecto se encuentra desarrollando dos líneas principales de actuación: por un lado, la revisión de la carta arqueológica del citado concejo con prospecciones y análisis LiDAR para descubrir nuevas tumbas y comprender mejor la evolución de las ya conocidas. Por el otro, excavaciones arqueológicas en lugares de interés con el fin de estudiar el grado de implantación de las primeras sociedades agropecuarias en el centro-occidente de la región (fig. 1). Mientras que esta última nos está dotando de un discurso histórico bien aquilatado en términos temporales, la renovación del inventario supone una necesidad perentoria en nuestra región; sobre todo porque los posicionamientos de los túmulos no suelen estar actualizados y, en la gran mayoría de los casos, no cuentan en el inventario regional con una georreferenciación por GPS ${ }^{1}$. Su ubicación en medio de parajes boscosos en los que puede haber sucesivas intervenciones forestales o industriales con adecuaciones del terreno, aperturas de pistas, etcétera, tampoco ayudan a una mejor conservación y protección de este patrimonio. Añade urgencia a dicha situación que estemos ante restos tan frágiles como olvidados en el noroeste peninsular. Por ello no resulta extrańo que la prensa se haga eco actualmente de constantes afecciones que dańan, de forma completa o parcial, las tumbas. No permanece al margen de esa tendencia general, extensible a territorios peninsulares y europeos, el concejo de Salas, como demuestran varios informes de alteraciones que dejaron un rastro administrativo, junto a las destrucciones mencionadas en la carta arqueológica. Un ejemplo, el de la Sierra de San Juan, nos basta para ilustrar algunas de las lamentables pérdidas, ya que en 1970 había once tumbas disgregadas en los dos kilómetros de desarrollo lineal de esta cumbre. En 1990 cinco de ellas ya habían desaparecido y de las conservadas algunas se vieron perjudicadas por trabajos forestales desarrollados a posteriori. Es tiempo, por tanto, de emprender acciones que permitan modernizar los catálogos y revisar la documentación disponible, en un momento en el que el bosque aún nos permite acceder, aunque sea con dificultades, a territorios y tumbas.

1 Aunque hay honrosas excepciones, como es el caso del inventario de concejos como Gijón, Tapia de Casariego o Pesoz (Sánchez \& Menéndez 2009; Montes 2013; Martín 2013), cuyos ayuntamientos han sufragado el coste de actualizar esta información. Conjuntos arqueológicos de máximo interés, como la necrópolis tumular de Monte Areo, catalogada como Bien de Interés Cultural también tienen sus posicionamientos revisados de una forma muy precisa (Sánchez \& Menéndez 2013). 


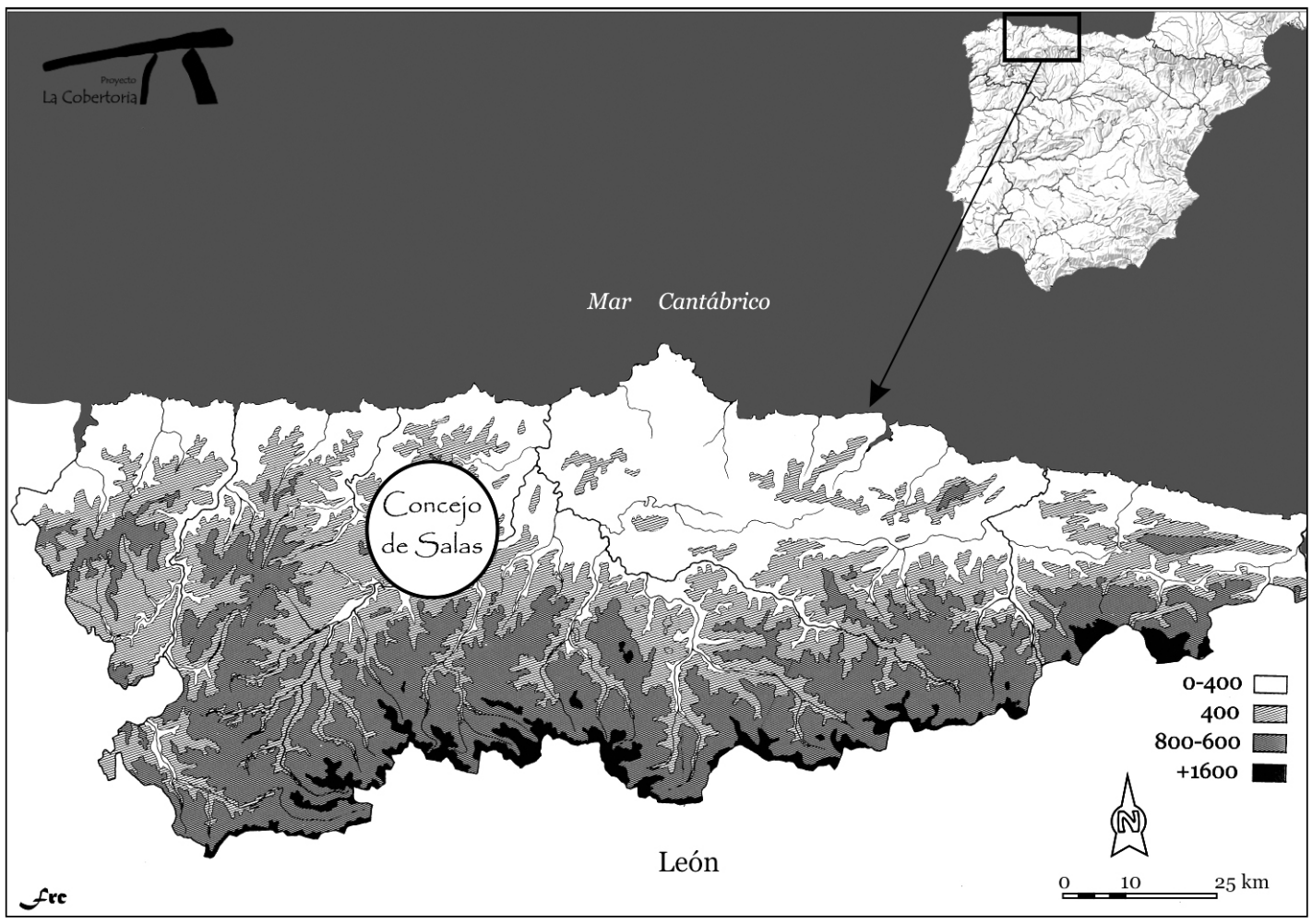

Figura 1. Mapa de Asturias con la ubicación del concejo de Salas en el cuadrante centro-occidental de la región.

\section{El PAISAJE ARQUEOLÓGICO: LAS NECRÓPOLIS TUMULARES ESTUDIADAS Y SU CATALOGACIÓN}

En este artículo se incluyen cuatro necrópolis tumulares agrupadas en dos grandes zonas (fig. 2). Por un lado, estarían San Juan y las Corradas, erigidas en las sierras noroccidentales de Salas, no excesivamente lejos de la capital salense. El otro sector objeto de atención ocupa el cuadrante suroccidental, en las proximidades de las divisorias con el concejo de Tineo. Las primeras catalogaciones de estos conjuntos fueron realizadas por José Manuel González y Fernández-Valles como parte de su extensa labor de campo. Así, las cuatro que aquí se analizan ya fueron incluidas en su Recuento de túmulos sepulcrales megaliticos de Asturias donde se indicaban las fechas de su identificación, entre 1969 y 1970 (González 1973). A partir de estos primeros registros se iría desarrollando, tanto en Salas como en el resto de la región, el inventario arqueológico, donde los datos recabados ya adquirieron un formato administrativo, reuniendo además las tumbas en necrópolis (De Blas 2006, 48). En el análisis que aquí se presenta están involucrados un total de veintinueve túmulos: una docena en Penausén, cuatro en Idarga, siete en las Corradas y los seis ya mencionados de San Juan. 


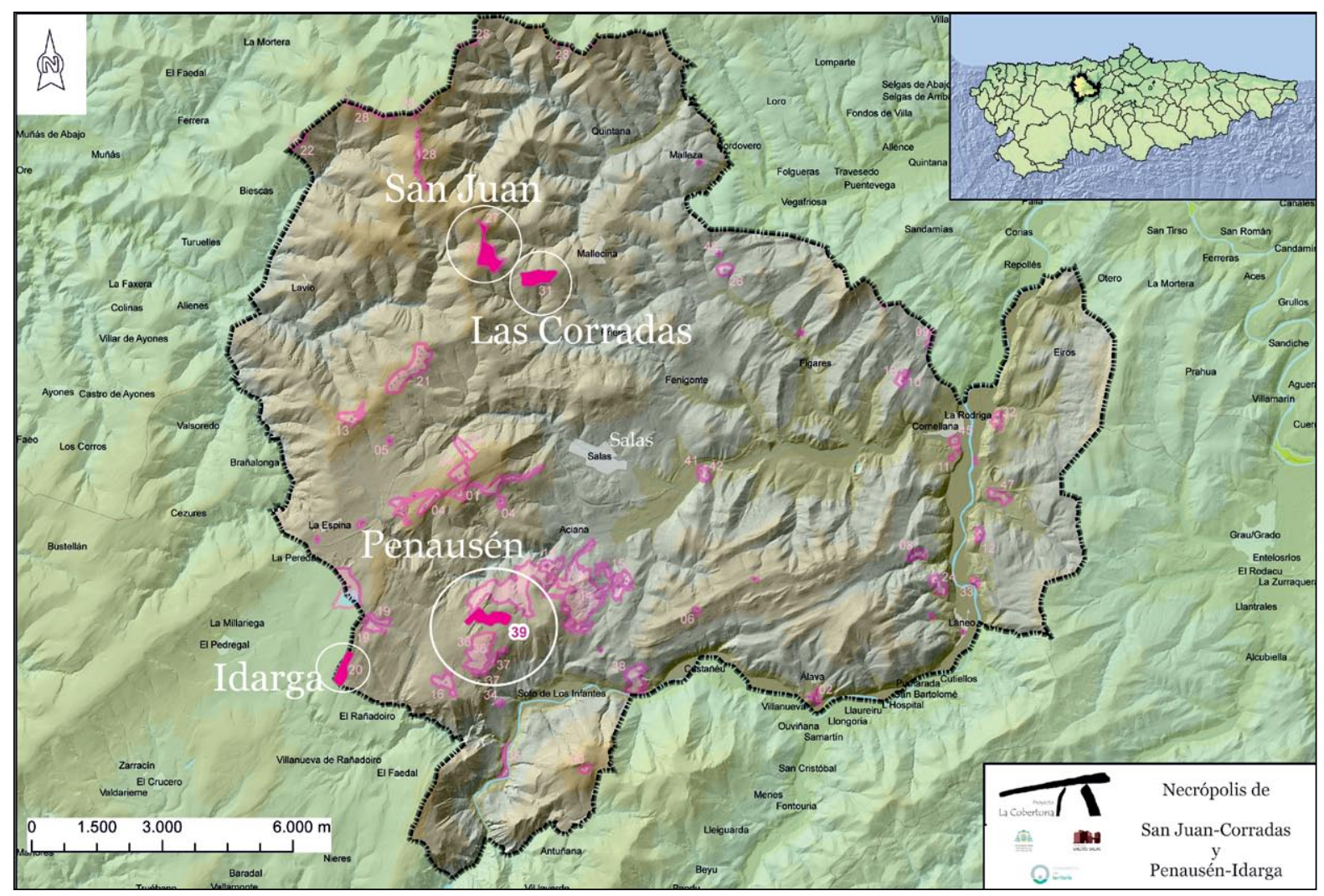

Figura 2. Plano del concejo de Salas con la ubicación de las cuatro necrópolis estudiadas.

\section{ANÁlisis LiDAR: unA TÉCNICA APLICADA AL MEgALITISMO ASTURIANO}

El LiDAR (Light Detection and Ranging) es, en la actualidad, una de las principales herramientas para la prospección arqueológica, hasta el punto de que ha sido definida como la innovación más importante en el campo de la adquisición e interpretación de datos desde la datación radiocarbónica (Bewley et al. 2005); fundamentalmente, por la habilidad que tiene para obviar la vegetación de la superficie del suelo (Bennett et al. 2011; 2012). En España, ha sido el Instituto Geográfico Nacional, mediante el Plan Nacional de Ortofotografía Aérea (PNOA), quien ha puesto a disposición pública los datos brutos LiDAR para su uso en abierto. Estamos ante un sistema activo que genera energía o pulsos láser con el objetivo de registrar geométricamente la superficie terrestre. Permite, pues, realizar mediciones y cálculos gracias a la emisión de un haz de luz sobre el terreno. Aunque el LiDAR es hoy bien conocido, abandonando ya el calificativo de "nueva tecnología», en la arqueología asturiana ha sido utilizado, especialmente, para localizar evidencias de campamentos romanos de las guerras astur-cántabras (Menéndez et al. 2013; Martín \& Camino 2018; Orejas et al. 2018). Este trabajo, como parte del proyecto de la Cobertoria, supone el uso de esta técnica por primera vez en el megalitismo regional asturiano, sumándose a una línea de investigación presente en otros territorios como Galicia (por ejemplo, Carrero Pazos et al. 2014; Carrero 2017) o el suroeste de la península ibérica (véase, por ejemplo, Martín et al. 2017, o Cerrillo \& Bueno 2019). 
Los datos LiDAR pueden ser clasificados según su altura, valor de intensidad, número de retorno, etc., elementos que permiten agrupar la vegetación del territorio en función de su altura (media/ alta/baja, a partir de criterios métricos establecidos por el investigador). Desde un punto de vista arqueológico, el elemento principal que marca la diferencia frente a otros métodos de teledetección como la fotografía aérea, es esa mencionada capacidad de eliminar la vegetación, así como el hecho de poder cartografiar de forma precisa el terreno baldío y sus formas superficiales.

Los datos LiDAR en nuestro país son de acceso libre a través del Centro de Descargas dependiente del Centro Nacional de Información Geográfica ${ }^{2}$ y cuentan, dependiendo de la zona, con una densidad de 0,5 puntos $/ \mathrm{m}^{2}$ para la primera cobertura (2008-2015), pudiendo llegar a densidades mayores en la segunda cobertura (2015-actualidad). El formato de descarga es LAZ, un formato de compresión de ficheros LAS. El estudio del terreno a partir de estos datos proporciona claros avances frente a los métodos tradicionales de prospección, ya que permite observar anomalías superficiales en una fase analítica previa al trabajo de campo. En territorios como Asturias o Galicia, en los que la masa vegetal es espesa y muy abundante, la prospección superficial intensiva resulta muchas veces imposible de realizar, por lo que acudir a un barrido del territorio que obvia la vegetación puede ser crucial a la hora de identificar nuevos túmulos megalíticos o revisar catálogos de monumentos antiguos (Carrero 2017).

\subsection{El tratamiento de los datos}

Los datos LiDAR utilizados en este trabajo se concretan en la creación de un modelo digital del terreno (en adelante, MDT), que cuenta con $1 \mathrm{~m}$ de resolución. El tratamiento de los datos LiDAR fue realizado con el software LAStools (Isenburg 2014), y el proceso de interpolación con SAGA GIS 6.2.0 (Conrad et al. 2015). Posteriormente se llevaron a cabo varios análisis de visualización para resaltar la microtopografía del terreno, con el uso del sombreado analítico (analytical hillshading) y filtro de remuestreo (resampling filter), ambos en SAGA GIS 6.2.0.

Por lo tanto, desde un punto de vista metodológico, este trabajo se concreta en la creación de un modelo digital topográfico de elevaciones a partir del cual se aplicarán, en SAGA GIS 6.2.0, filtros de visualización que permiten resaltar las formaciones microtopográficas del terreno e identificar los túmulos megalíticos. Para conseguir el MDT sin vegetación utilizamos la herramienta lasground de LASTools, que clasifica la nube de puntos LiDAR en puntos del terreno (bare-earth, o suelo desnudo - clase 2-), y aquellos que no pertenecen al terreno (clase 1, correspondiente a estructuras y vegetación). Posteriormente, las2las filter nos permite extraer solo aquellos puntos correspondientes al terreno, creando, de esta forma, una malla de puntos tridimensional que solo contiene los del terreno (sin vegetación ni estructuras). A partir de aquí, se realizó en SAGA GIS 6.2.0 una interpolación para crear el MDT, utilizando, finalmente, el analytical hillshading y resampling filter para revisar la presencia o ausencia del elemento tumular y su localización topográfica. Todos los resultados fueron comprobados en campo durante varias jornadas de prospección arqueológica.

\section{Descripción Pormenorizada de las necrópolis y Cotejo del LiDAR con los trabajos DE CAMPO}

El estudio de los datos LiDAR fue la primera fase analítica y conforma un tipo de trabajo identificado en la actualidad como "prospección remota», labor que siempre es previa a los reconoci-

${ }^{2}$ https://pnoa.ign.es/presentacion 
mientos sobre el terreno ya clásicos en la arqueología. Esa labor «remota» se concreta en cotejar sus resultados en el campo para ver el grado de eficacia del método. Incluiremos, a continuación, una descripción más detallada de cada agrupación de túmulos desde el punto de vista geográfico, junto con los resultados preliminares que el LiDAR aportó.

\subsection{San Juan}

La necrópolis está ubicada en la zona noroccidental del concejo en una elevación cuyo principal eje serrano, de casi dos kilómetros de desarrollo en línea de aire, sigue una dirección N/NW-S/ SE. El núcleo tumular referenciado en la carta arqueológica bajo el nombre de San Juan hace en realidad referencia al bloque occidental de la sierra, sector que tiene casi un kilómetro de extensión (fig. 3). La otra mitad la ocuparía el sector oriental, separado del occidental por la llamada Campa de San Juan; tanto la campera como este tramo oriental se ubican en una peana altimétrica más baja. Quizá por eso el tramo levantino de la sierra se desgajó en la carta arqueológica como un elemento independiente: la necrópolis o cordal de las Corradas que analizaremos en el siguiente epígrafe. Todo ello a pesar de los lazos geológicos que comparten las dos mitades, y de que ambas albergaron sendos cementerios prehistóricos.

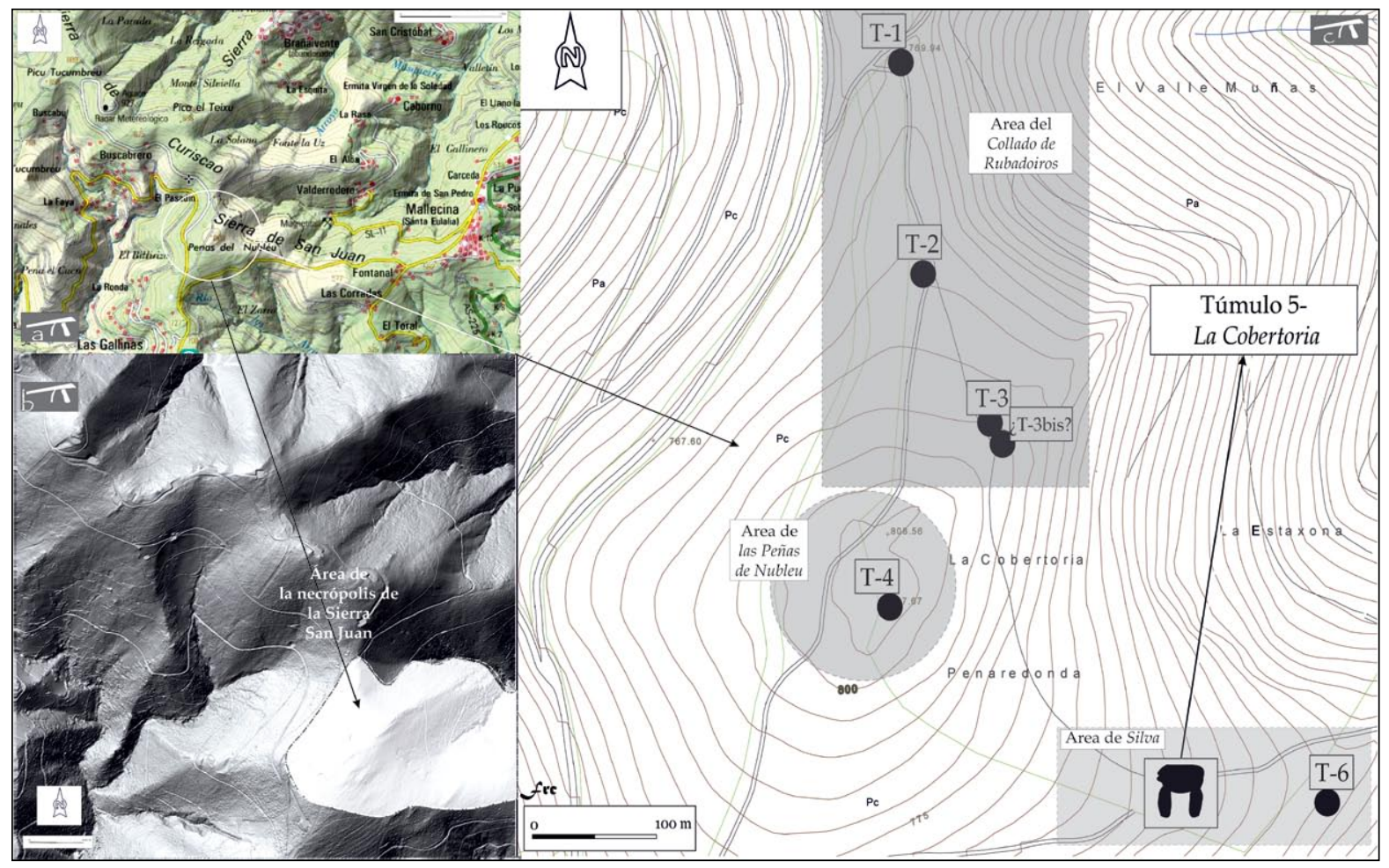

Figura 3. Necrópolis de San Juan: a) Plano topográfico (sobre cartografía de base del IGN@); b) MDT con el área general de la necrópolis; c) Planimetría con la distribución de elementos y las tres grandes agrupaciones diferenciadas en este lugar. 
San Juan conserva actualmente seis estructuras distribuidas en tres grandes paisajes dentro de la sierra: una partición heredada desde el inventario de J. M. González que se vio más difuminada en la carta arqueológica de la zona, pero que estamos recuperando de nuevo en vista del sentido topográfico y espacial que tiene tal división (R. del Cueto \& Carrero, en prensa). Las tres grandes agrupaciones definidas en 1970 son las siguientes:

a) Collado de Rubadoiros, en la parte noroccidental de la sierra y con tres estructuras conservadas.

b) La cúspide de la montaña en su zona central, asociada al topónimo de Penas de Nubleu: un importante afloramiento ahí localizado que pudo servir de fuente de aprovisionamiento de piedra para uno, o varios, de los conjuntos tumulares (R. del Cueto \& Carrero, en prensa).

c) El tercer y último subconjunto, en la zona denominada de Silva, estaría en la ladera oriental de San Juan y engloba el túmulo cinco, en el sitio de La Cobertoria (R. del Cueto \& De Blas 2018; R. del Cueto \& Busto 2020), y la estructura seis no lejos de este último.

El sentido de ese fraccionamiento quizá esté marcado por la lógica, quizá por la organización y desarrollo de las prospecciones llevadas a cabo hace cincuenta años. Sea como fuere, en este trabajo proponemos recuperarlo, ya que no se pueden soslayar las evidentes separaciones físicas (visuales y topográficas) que tienen estos tres subgrupos. Así ocurre en el collado de Rubadoiros, asociado de forma clara a un paso que divide San Juan con la sierra de Curiscao. Un vínculo que justificaría la presencia de uno de los túmulos en el entorno de esa vía de comunicación; mientras, los otros dos (el dos y el tres) aunque están en zonas de media ladera, también miran claramente hacia el collado.

La planicie superior estuvo monopolizada por el conjunto de Penas de Nubleu, donde González localizó cuatro estructuras en la década de 1970, de las que hoy solo se conserva una. La abundancia de canteras en las inmediaciones de este conjunto, tanto las señaladas peñas como otras crestas rocosas de menor entidad, podría justificar la alta concentración de túmulos en este tramo de la montaña, el de mayor dominio visual, a ambas vertientes. Un patrón locacional que parece encontrar puntos en común con otras áreas geográficas (Bradley 1991; Carrero et al. 2019).

Por lo que respecta al conjunto de Silva estaría concentrado en la ladera oriental y también perdió al menos dos estructuras debido a la intensa actividad forestal registrada en la zona entre los años setenta y los noventa del pasado siglo. La posible relación de las tumbas con vetas rocosas y su clara orientación hacia la zona media del valle y los actuales núcleos de Valderrodero o, especialmente, Mallecina y su vega, ya se ha insinuado recientemente y se encuentra bajo estudio ( $\mathrm{R}$. del Cueto \& Carrero, en prensa).

Todo este posicionamiento, con la mencionada segmentación tripartita de la actual necrópolis, podría encontrar explicación dentro del argüido e ineludible binomio tumba-territorio (Bradley 1998, 14; Fábregas \& Vilaseco 2003, 290-291), que aquí se ve refrendado además por la nula interconexión visual que hay entre los distintos sectores, que ejercen casi como unidades visuales estancas. Los datos que aportó el LiDAR en esta necrópolis permitieron avanzar en la estimación de los volúmenes tumulares ( $\mathrm{R}$. del Cueto \& Carrero, en prensa) y en la identificación actual de los mismos y sus características, aunque resultaron parcos en nuevos hallazgos. Tampoco facilitaron información sobre posibles retazos de las cinco tumbas desaparecidas en los sectores de Penas del Nubleu y Silva. 


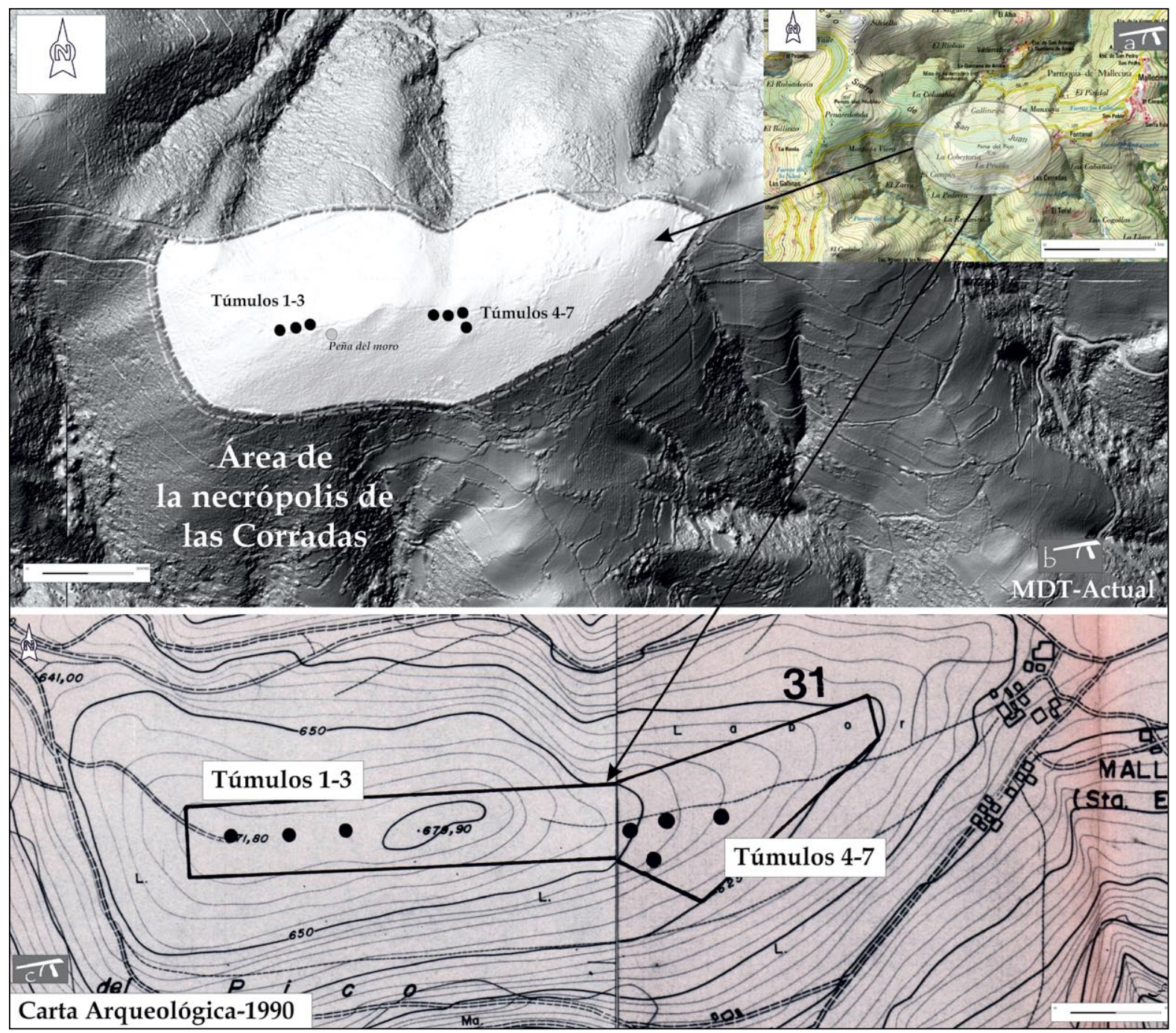

Figura 4. Necrópolis de las Corradas: a) Plano topográfico (sobre cartografía de base del IGNC); b) MDT con el área general de la necrópolis; c) Distribución de elementos en la cartografía del inventario arqueológico.

\subsection{Cordal de las Corradas}

Como ya comentamos, en el tramo suroccidental de la sierra de San Juan se desgaja una elevación separada del principal bloque serrano por una pequeña llanera denominada Campa de San Juan, un topónimo que sirvió para referenciar durante cierto tiempo al dolmen de La Cobertoria, no muy alejado de la campera, aunque sí separado en altura de esta (De Blas 1983). En ese estrecho rellano de transición también se construyó una capilla con advocación al santo que da nombre a la sierra ${ }^{3}$, quizá con la intención de cristianizar un espacio de hondas tradiciones paganas,

${ }^{3}$ Los vecinos de Mallecina aún conservan el recuerdo de la localización aproximada de las ruinas de la capilla, elevada sobre la actual carretera y hacia el lado norte de esta, una edificación que lleva sin culto más de medio siglo. 
pues separaba dos necrópolis tumulares distintas. La principal la acabamos de describir en el anterior epígrafe, pero en las inmediaciones de este cruce de caminos, se elevaba el llamado cordal de las Corradas, que da nombre a un segundo cementerio y que, por ello, será tratado de forma individualizada (fig. 4).

Los elementos arqueológicos conservados en las Corradas (siete en total) se disponen agrupados en dos subconjuntos que ocupan, en ambos casos, la cúspide del cordal. La plataforma superior del mismo no es excesivamente ancha (alrededor de unos 50 metros) aunque sí es bastante prolongada (entre 250 y 300 metros, aproximadamente). Una morfología que fue aprovechada por los grupos que erigieron aquí sus tumbas y que se mostraron especialmente interesados en ese eje central, que es el de mayor relevancia y visibilidad.

En el extremo occidental del cordal se concentran los tres primeros túmulos siguiendo una clara alineación, separados entre 25 y 35 metros, aproximadamente. Los cuatro restantes fueron construidos a escasa distancia entre sí en el extremo oriental de la elevación, apartados por completo de los tres primeros. Una pequeña cúspide del terreno, denominada Peña del Moro, separa ambas agrupaciones, y este singular topónimo ejemplifica la profunda carga legendaria existente en Las Corradas, tal como han puesto de relieve los trabajos del filólogo Jesús Suárez $(2001)^{4}$. Además, la Peña del Moro no solo fue fuente de leyendas: pudo ser utilizado de divisoria topográfica y quizá de cantera de alguna de las estructuras. Todo ello pese a que no hay un afloramiento masivo de rocas, aunque sí abunden en este punto cuarcitas propias de la formación Cándana, rocas que se utilizaron para rellenar las masas de los túmulos uno, dos y tres. No sabemos si, en este caso, la pista construida para la plantación del pinar pudo ocultar alguna cresta rocosa más, aunque la poca altura de la plataforma no parece esconder excesivo terreno. No obstante, al sur de la pista aún resulta visible uno de los bloques del afloramiento que tiene incluso una pequeña cazoleta en su parte superior, conjunto ya reseñado en el inventario arqueológico (Rodríguez 1990; ficha 31).

En términos de la cuantificación arqueológica del lugar no debemos olvidar que, de nuevo, volvemos a tener una significativa variación en el número de estructuras, pues de los once túmulos identificados en 1970 pasamos a tan solo siete estructuras en 1990. Todos desaparecieron antes de la gran plantación realizada en 1997 o 1998, aproximadamente. En este caso además los datos LiDAR proporcionaron falsos positivos al identificar como túmulos elementos que, en realidad, eran el resultado de una serie de modificaciones recientes en el cordal; lo que nos lleva, de nuevo, a llamar la atención sobre la necesidad de contrastar los datos de esta prospección remota con la observación directa en campo.

\subsection{Penausén}

Las dos próximas necrópolis de nuestra descripción, Penausén e Idarga, se encuentran en el cuadrante suroccidental del concejo de Salas, y distan entre sí unos tres kilómetros y medio en línea de aire. El conjunto de Penausén o Chamas de Penousen ocupa un rellano menor al pie del Alto de Calabazos, integrado en la sierra de Carrales. En los piedemontes del alto se identificó una concentración notable de estructuras: cuatro de ellas aparecieron al sur del Calabazos durante la realización de la carta arqueológica para ser agrupadas en un sector denominado escalera por su forma

\footnotetext{
4 En la sierra de Las Corradas, en la Peña'l Moro, decian que ahi que habia un tesoro. $Y$ decía mi madre que en la sierra, donde habia una yalga o que habia oro, que a lo mejor llevabas el ganáu alli a pastar, y en el sitio
}

que se echaba si habia una yalga que la vaca que salia pinta, que traía una mancha pinta (texto original extraído de: Suárez 2001, 181). 
aterrazada (Rodríguez 1990; ficha 36). La plataforma norte y noreste es la que se corresponde con la necrópolis de Penausén, donde José Manuel González había identificado diez túmulos a los que se sumaron otros dos con la realización del inventario (fig. 5). Uno de ellos, el número ocho, había desaparecido casi por completo en el año 90 y en la actualidad resulta imposible su identificación. La pista que une la Bouga con el Pevidal y sus sucesivas ampliaciones posiblemente acabaron con los restos que se conservaban de esa tumba prehistórica.

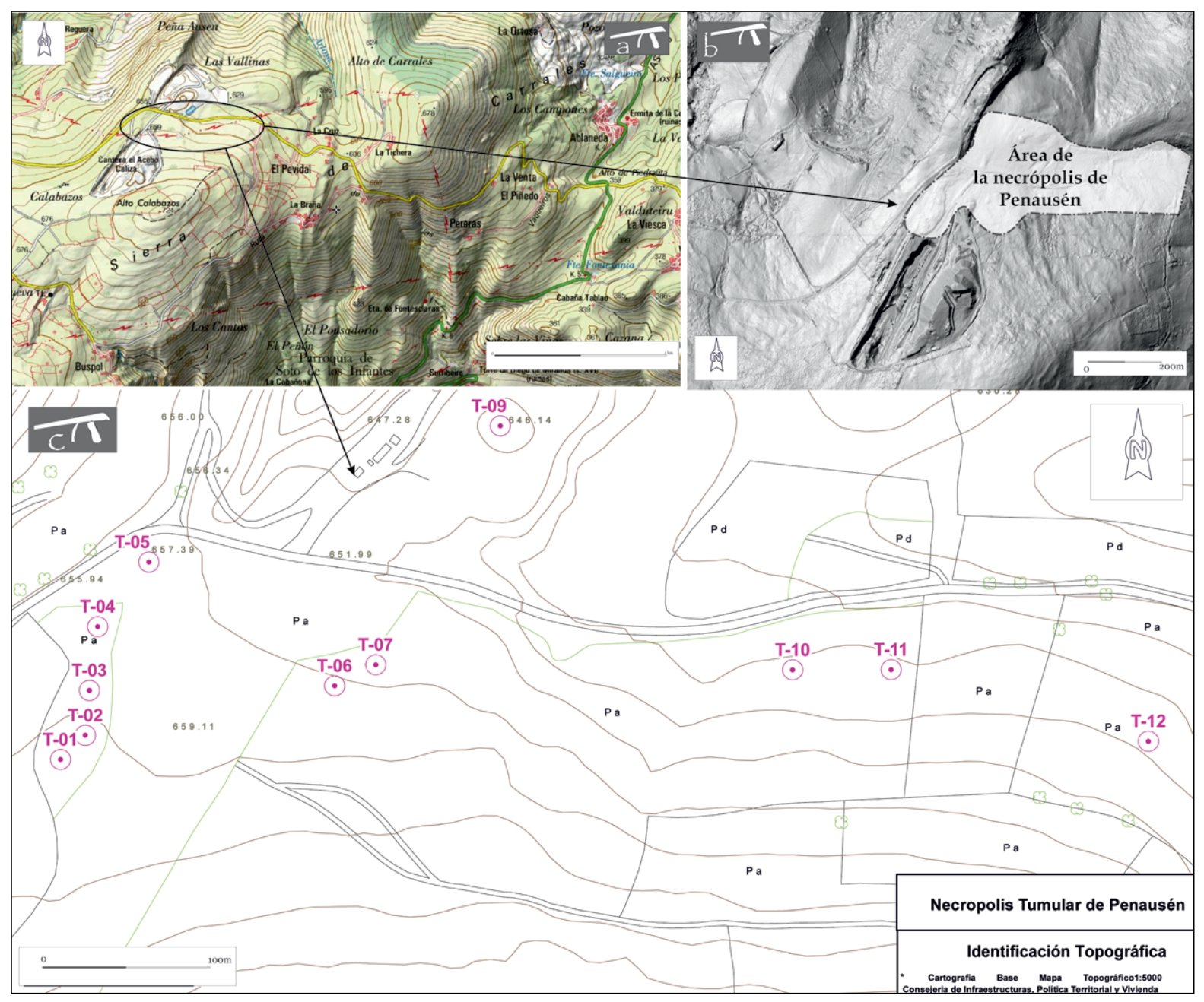

Figura 5. Necrópolis de Penausén: a) Plano topográfico (sobre cartografía de base del IGN@); b) MDT con el área general de la necrópolis; c) Planimetría con la distribución de elementos.

La distribución del espacio funerario parece determinar al menos dos ejes constructivos principales: así, mientras que los túmulos uno a cinco siguen una alineación de unos 150 metros en sentido N-NE/S-SW, los numerados del seis al doce también están afrontados, pero con una orientación E/W a lo largo de unos 600 metros de recorrido. El primero de los conjuntos es el más 
conocido y atrajo también la atención de los expoliadores que exhumaron parte de una de las cámaras de enterramiento. En 1976, el profesor Miguel Ángel de Blas Cortina iniciaría su investigación sobre el megalitismo asturiano en esta necrópolis, que desarrollaría durante más de cuatro décadas. Los resultados estratigráficos y el estudio de las arquitecturas sepulcrales recuperadas fueron publicados al poco tiempo (De Blas 1978; 1980). Los análisis LiDAR incorporaron poca información a esta base documental ${ }^{5}$, aunque sí permitieron iniciar un estudio de los volúmenes tumulares que quizá nos lleve a comprender mejor la evolución del cementerio (R. del Cueto \& Carrero, en prensa).

\subsection{Idarga}

La sierra de Idarga, que da nombre a la necrópolis, forma un bloque elevado con desarrollo longitudinal en dirección S/SW a lo largo de más de tres kilómetros. En la actualidad, más de un kilómetro de esta montaña ejerce de divisoria entre el extremo occidental de nuestro concejo de estudio y los bordes orientales del de Tineo. La elevación es estrecha y alargada y, como ocurre con buena parte de las sierras occidentales de Salas, tiene la propensión a ser alomada o aplanada en su parte superior (Mangas 1992, 54). Las cuatro tumbas aquí construidas no parece que pretendiesen ocupar las cotas más altas, conformándose con un escalón inferior, inmediato a la planicie superior, en el borde meridional de la montańa. Una posición que, o bien está vinculada a las comunidades prehistóricas, o bien a los territorios a los que las tumbas se orientan, ya que semejante posicionamiento dejó la necrópolis de espaldas (y oculta) a los terrenos de la Turbera de la Molina, ${ }^{6}$ o a la penillanura en la que actualmente se ubica el pueblo de la Espina. El territorio funerario se encara, sin embargo, hacia los suaves terrenos que quedan al oeste del cementerio prehistórico, ya en la demarcación administrativa de Tineo, y también lo hace a todo su flanco meridional. Sin embargo, gracias a la suficiente altura en la que fue construido, algunas de las tumbas, especialmente la número uno, cuentan con amplias panorámicas (fig. 6).

Cinco túmulos fueron identificados en la década de 1970 por J. M. González: cuatro en la ladera meridional de Idarga y uno en las divisorias con Tineo en el enclave del Pan de la Vara, que ya había desaparecido cuando se elaboró el inventario del concejo (Rodríguez 1990; ficha 20). De los cuatro restantes tres presentan relieves muy atenuados por lo que el uso del LiDAR resultó en este caso crucial.

\footnotetext{
5 Por ese motivo se omiten las consideraciones a este conjunto en el epígrafe de resultados y valoraciones.
}

6 Estudiada en profundidad muy recientemente (Martínez et al. 2016). 


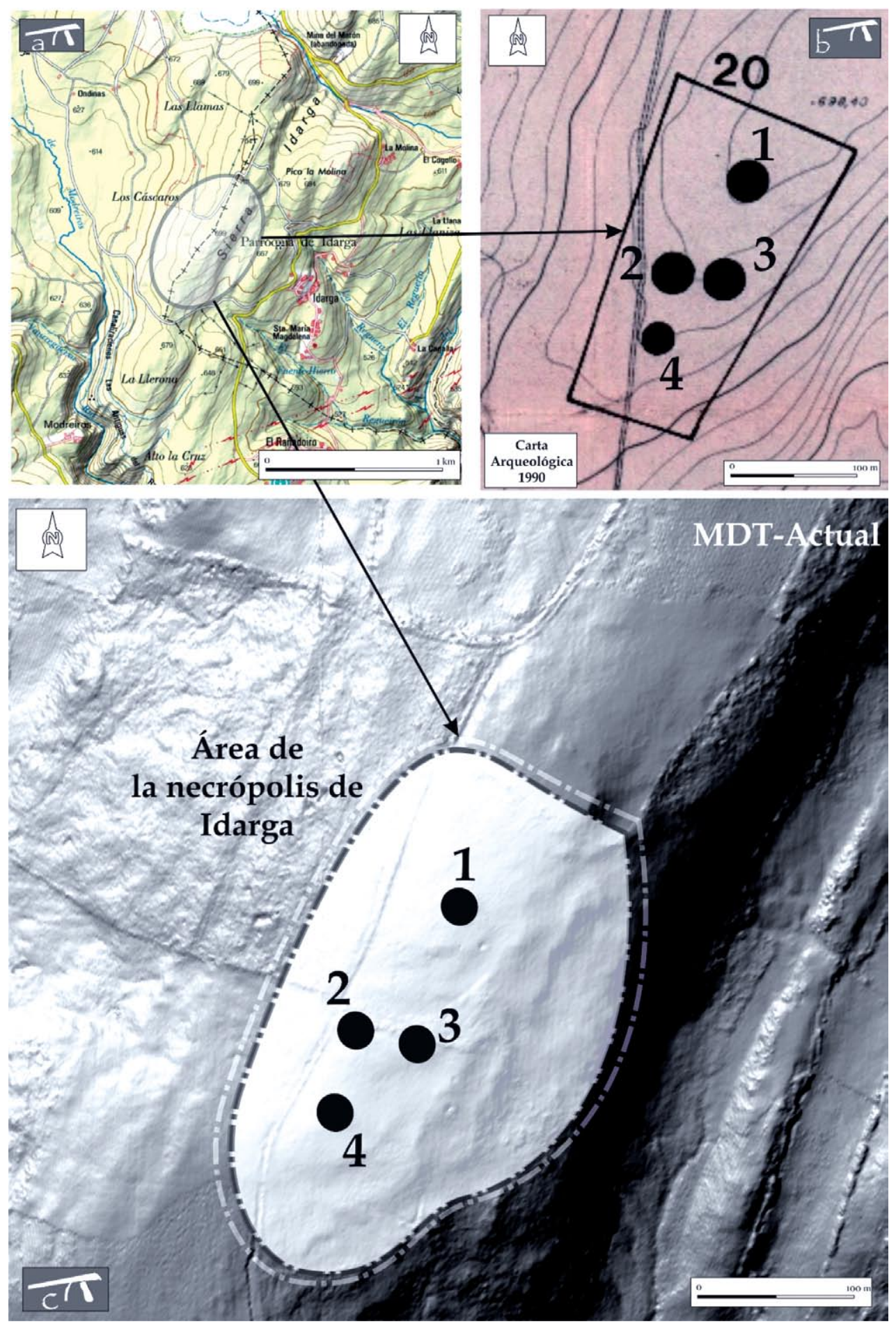

Figura 6. Necrópolis de Idarga: a) Plano topográfico (sobre cartografía de base del IGN(); b) Distribución de elementos en la cartografía del inventario arqueológico; c) Plano topográfico MDT con el área general de la necrópolis. 


\section{Resultados y VAlORACIONES PRELIMINARES}

La aplicación por primera vez en Asturias del LiDAR al estudio de las necrópolis megalíticas resultó de gran interés, al incrementar en la gran mayoría de los casos la información disponible para su estudio. Haciendo un balance por cementerios y conjuntos podemos apreciar, no obstante, una repercusión distinta. En San Juan, por ejemplo, tenemos que citar la ayuda que supuso en la identificación de estructuras que hoy en día están dañadas y bastante ocultas por la vegetación de monte bajo. Es el caso de la número dos, ubicada en el entorno del collado de Rubadoiros en zona de media ladera. La tumba fue cruzada a la mitad por un camino que, afortunadamente, no abrió mucha caja en su trazado. Aun así, la senda dividió el montículo en dos secciones, quedando el segmento occidental en unos inapreciables veinte centímetros de altura. Dado que la vegetación suele levantar mucho más del suelo, ese tramo del túmulo queda muy oculto y solo se aprecia si uno ha consultado previamente el LiDAR. Sobre todo porque la fotografía de la carta no resulta aquí de utilidad: el terreno varió tanto y el camino se amplió hasta tal punto que la imagen de 1990 tiene poco que ver con la realidad actual. Además, un extenso pinar cubre la otra mitad de la tumulación, la oriental, factor que tampoco ayuda a la rápida identificación de una estructura que, por dimensiones, debería ser fácil de reconocer (fig. 7).

En este mismo sector de la necrópolis el LiDAR también resultó crucial para corregir una adenda que sufrió recientemente el inventario arqueológico, ańadido que ha tenido incluso repercusión administrativa con la inclusión de un elemento bastante dudoso en el catálogo patrimonial del Plan General de Ordenación Urbana del concejo. Durante la construcción del parque eólico sito en la sierra, un informe arqueológico estableció que a la estructura número tres, ya reconocida desde los 70, debía añadírsele otra posible tumulación que luego empezaría a figurar en catálogos y documentos administrativos como "túmulo tres-Bis» (Santos 2004). A pesar de que la densa vegetación añade confusión y dificulta reconocimientos claros, resultaba curioso que esta segunda estructura hubiera pasado inadvertida al arqueólogo que elaboró el inventario en 1990. Sobre todo porque este catálogo se realizó, al igual que los reconocimientos de 1970 de J. M. González, en momentos en los que la sierra era un terreno de pastizal abierto donde los túmulos producen relieves inconfundibles (fig. 8). 


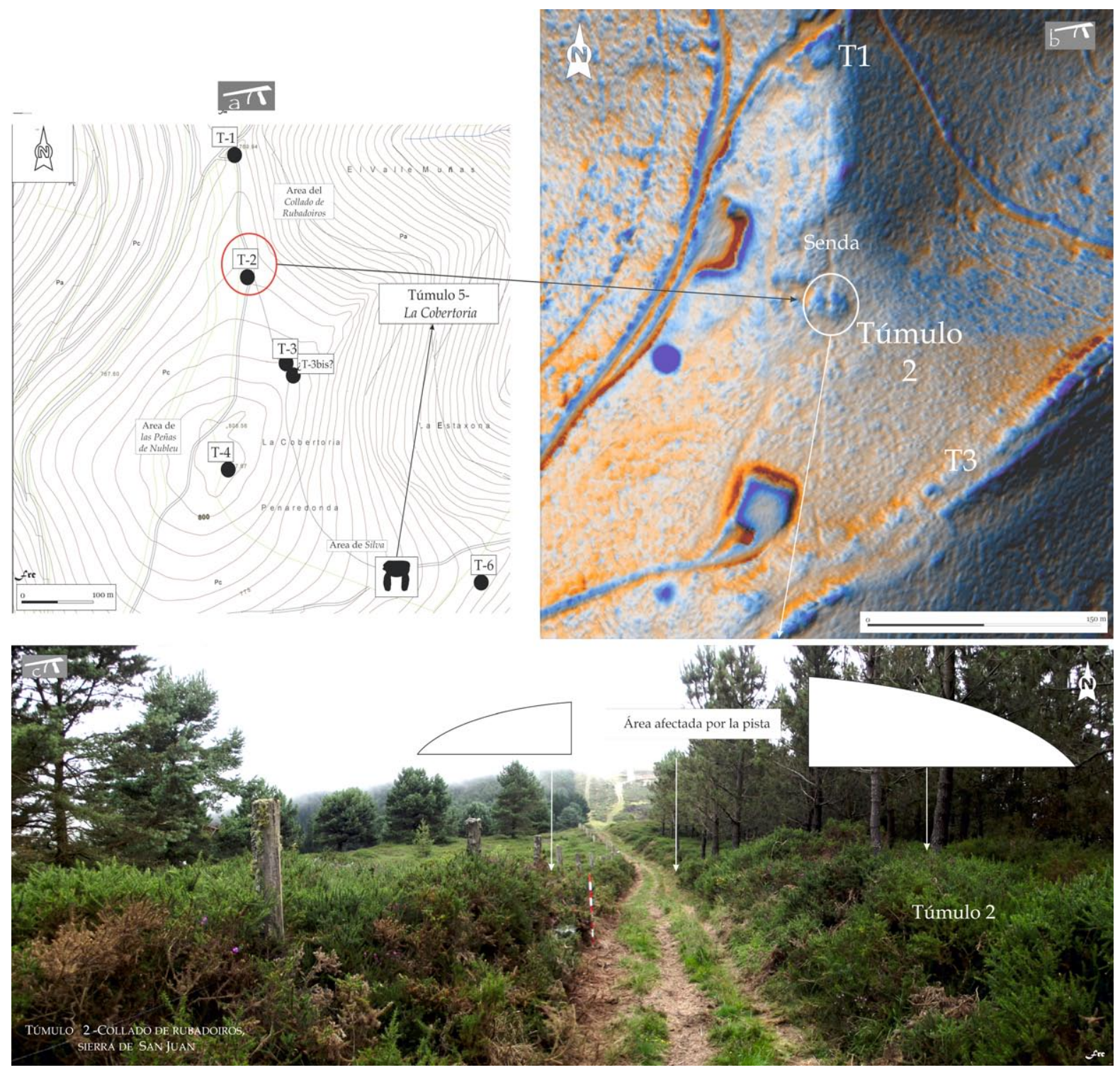

Figura 7. Necrópolis de San Juan: a) Plano topográfico con el túmulo dos señalado en el conjunto; b) Imagen LiDAR con la indicación al túmulo dos; c) Fotografía con la escasa visibilidad de la estructura debido a la afección de una pista y la elevada vegetación. 


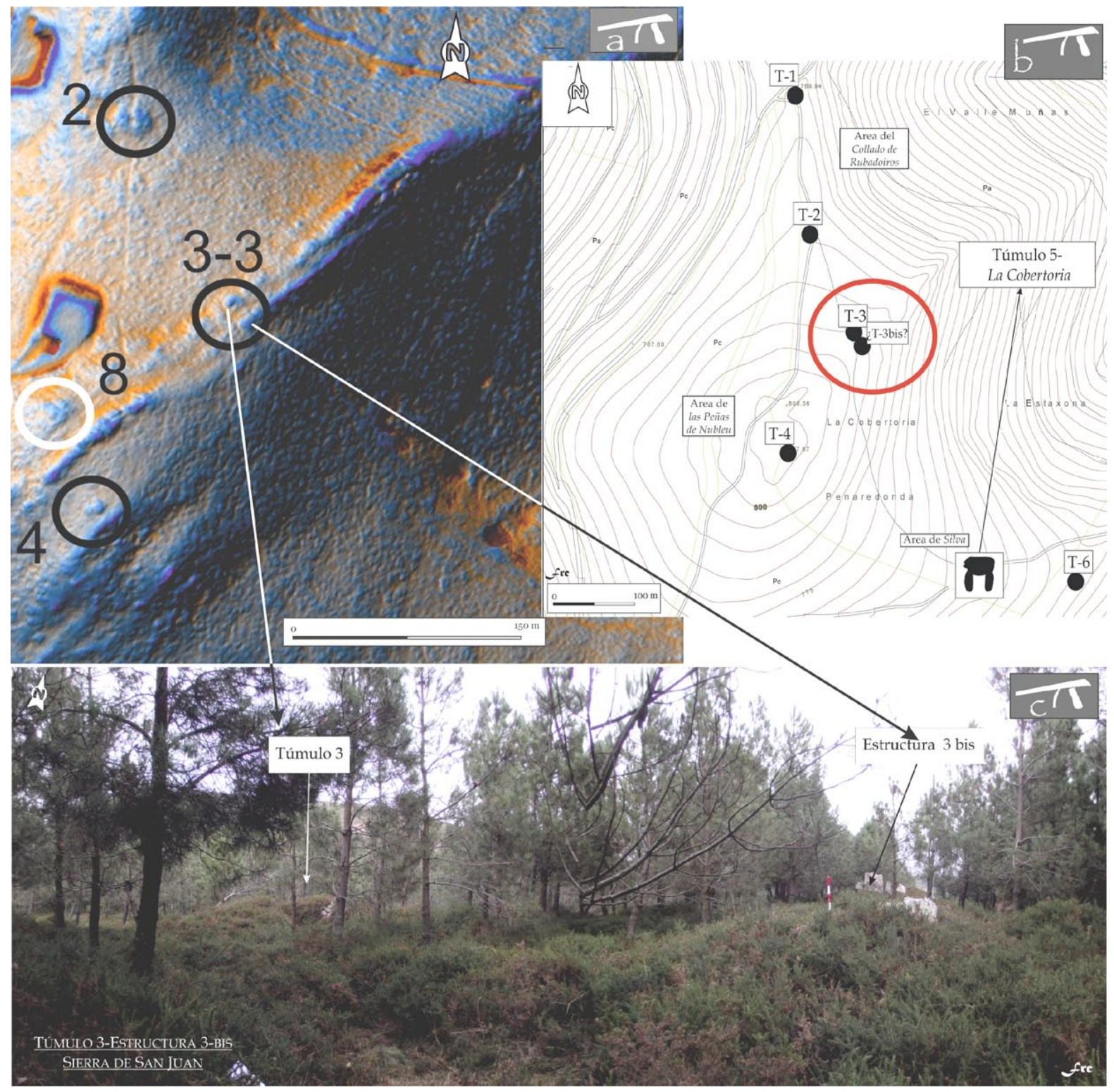

Figura 8. Necrópolis de San Juan: a) Plano topográfico con el túmulo tres señalado en el conjunto; b) Imagen LiDAR con la indicación al túmulo tres y la dudosa estructura tres bis; c) Fotografía panorámica de ambos sectores. 
El Modelo Digital del terreno generado a partir de los datos LiDAR, junto con la prospección en campo y la consulta de la información del inventario, permitió comprobar que es bastante probable que la adenda no corresponda con ninguna estructura prehistórica. Más bien parece la continuidad de un extenso afloramiento cuarcítico que sí podría haberse utilizado como cantera, dado que el abultamiento dista apenas unos 15 metros del túmulo tres. Ni la entidad sobre el terreno ni las características de la piedra, cuyas irregularidades son más propias de resaltes naturales que de una estructura antrópica, indican la existencia de intenciones constructivas, lo cual explicaría que un ojo experto como el de J. M. González ignorase este punto, aunque sabemos con seguridad que sí estuvo allí.

Ninguna información procedente de los análisis de visualización sobre datos LiDAR nos permitió reconocer la posible ubicación de alguna de las antiguas tumbas destruidas en la necrópolis de San Juan entre la década de 1970 y la de 1990 (vid. supra). Es evidente, no obstante, que resultarán difíciles de recuperar: al menos de momento y con las técnicas actuales. Quizá porque aquí las replantaciones fueron ejecutadas mediante profundos bancales que modificaron por completo las zonas de ladera.
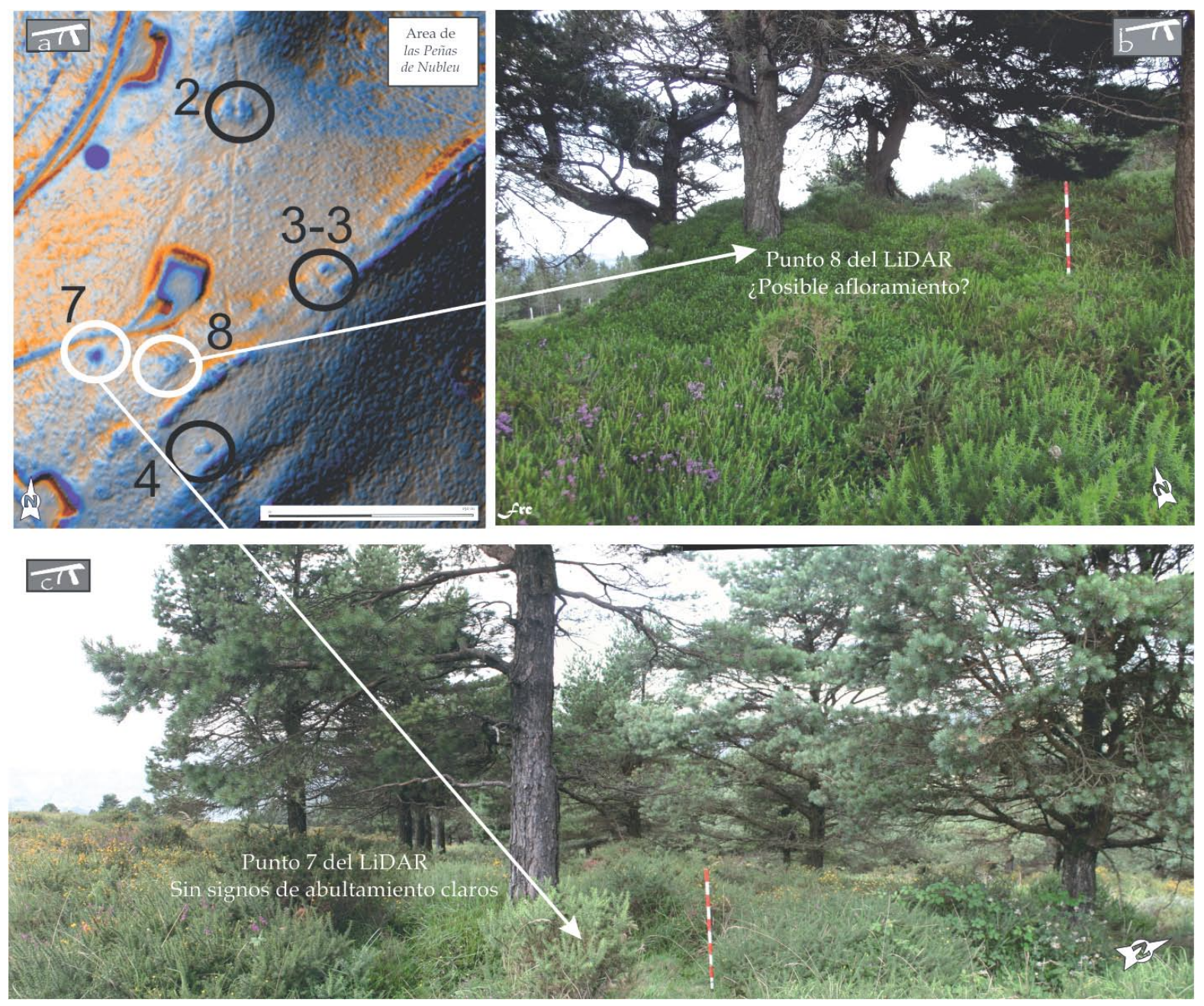

Figura 9. Necrópolis de San Juan: a) Imagen LiDAR que señala las dos nuevas localizadas que detecta la herramienta; b) Imagen de la zona del punto ocho; c) Imagen de la zona del punto siete. 
En cuanto a las nuevas localizaciones señaladas por el LiDAR en San Juan, que se ubican en el cuadrante central de la sierra y en su zona alta (puntos 7 y 8; fig. 9), hemos de decir que tampoco parecen corresponderse con estructuras prehistóricas. Una de ellas nos conduce, de nuevo, a un afloramiento que entronca con la extensa veta visible en la zona alta de la sierra y que no está lejos de las denominadas Penas de Nubleu. Si bien resulta imposible el reconocimiento visual íntegro del punto que señala el LiDAR, por encontrarse este cubierto de maleza, la coincidencia y proximidad a otros afloramientos y la irregularidad y escasa elevación de su casquete parecen más indicativos de una naturaleza geológica que arqueológica. Quizá una simple limpieza del lugar o una excavación puedan resolver con claridad la duda. A escasa distancia de este punto, los resultados del LiDAR indican otro que apenas cuenta con formas llamativas en el terreno y que, al encontrarse en un sector ya objeto de plantación, podría responder más a acciones recientes que prehistóricas. Por último, ante estructuras poco claras como el túmulo seis de San Juan, que presentaba ciertos problemas de identificación, la técnica tampoco resultó de ayuda. En este caso, la tumba presenta escasa altitud, se encuentra en un terreno con diversos abultamientos naturales y además está inmersa en una plantación que zanjeó parcialmente el enterramiento. Elementos de confusión que provocaron que identificásemos en un principio el sitio arqueológico más al sur, relacionándolo con una pequeña escombrera del camino o de la plantación, en una zona baja y alejada de su sitio original. La posición original es, en realidad, una elevación muy afilada y poco aplanada pero que es el sitio más lógico para ubicar un túmulo y donde sí que localizamos, mediante prospección de campo, el punto señalado en el inventario arqueológico como túmulo seis.

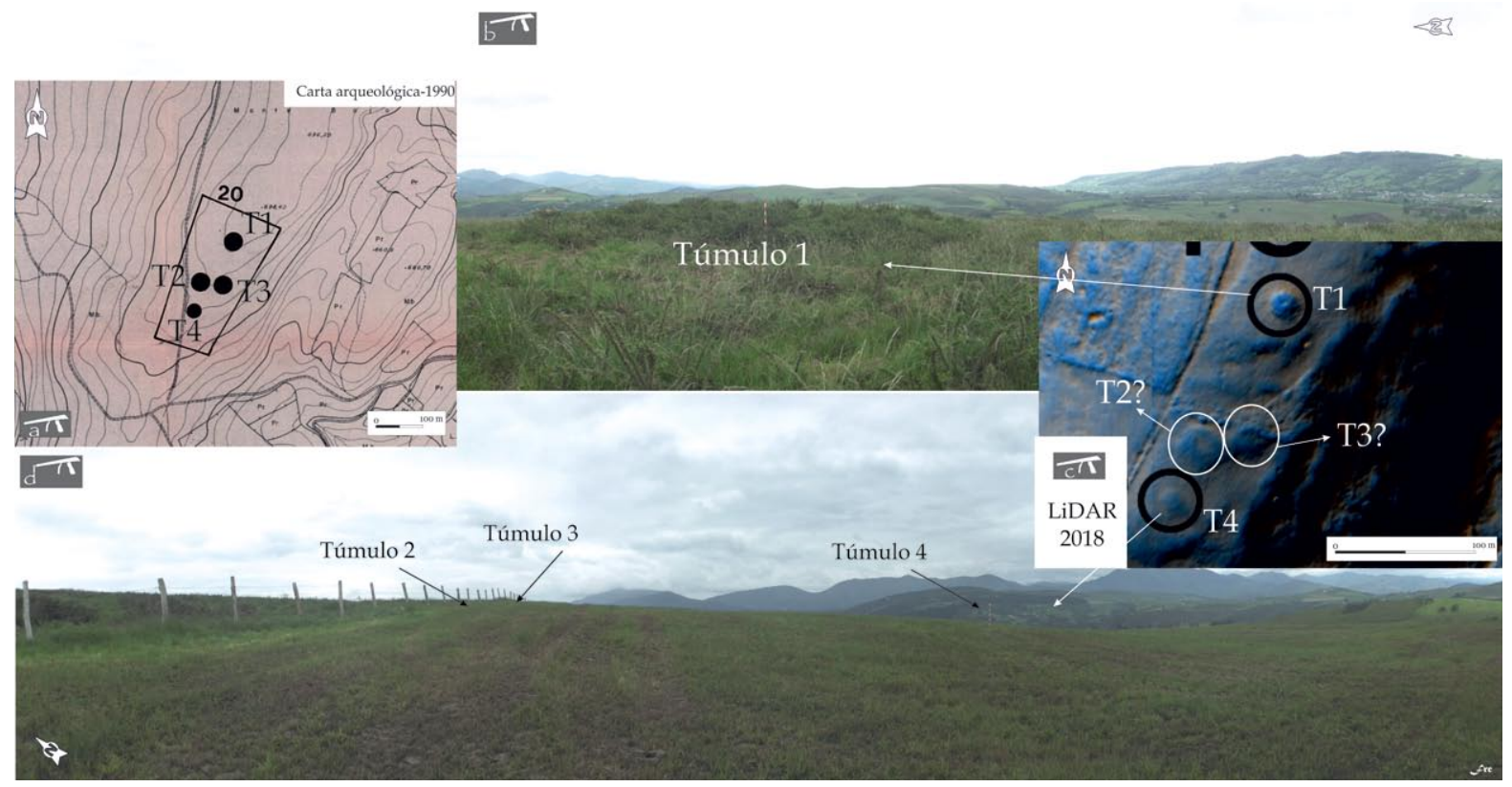

Figura 10. Necrópolis de Idarga: a) Distribución de elementos en la cartografía del inventario arqueológico; b) Imagen panorámica del túmulo uno; c) Imagen LiDAR con los cuatro túmulos resaltados; d) Imagen panorámica de las tres estructuras restantes, apenas perceptibles ya sobre el terreno.

\footnotetext{
7 Como ya mencionamos anteriormente, se omite el comentario de la necrópolis de Penausén porque no
}

hay nuevas localizaciones ni otra información de interés acerca de este conjunto. 
Aunque los trabajos en la necrópolis de Idarga aún se encuentran en desarrollo y no han concluido, la aplicación a este conjunto de tumbas de diferentes tratamientos analíticos basados en datos LiDAR resultó altamente positiva; al margen de algunas nuevas localizaciones, de las que se está comprobando su grado de correspondencia con estructuras arqueológicas, la herramienta está resultando clave al menos en la identificación nítida de tres de las cuatro tumbas del cementerio prehistórico (fig. 10).

Por último ${ }^{7}$, en la necrópolis de Las Corradas hemos apreciado de forma evidente tanto las ventajas como las desventajas de esta metodología digital, y quizá es uno de los lugares que demuestra de una forma más contundente la necesidad de combinar el tratamiento de prospección remota con la más convencional. Los tres primeros túmulos de la necrópolis, que aún conservan parte de su estructura y que forman (como indicamos anteriormente) un alineamiento en la cumbre de sierra, no fueron detectados en las imágenes derivadas del LiDAR. Aquí, sin duda, la ampliación de la pista realizada para el pinar plantado en el cordal modificó tanto las estructuras arqueológicas como el trazado del viejo camino que ya cortaba algunas de las tumbas, como señaló en su momento el inventario arqueológico (Rodríguez 1990; ficha 31). La caja de la pista, de mayor anchura y profundidad, vino a modificar las superficies y a confundir las apreciaciones basadas en el modelo digital del terreno y los tratamientos posteriores. La segunda limitación registrada en la prospección remota de Las Corradas debe entenderse de nuevo en el contexto de la plantación: la pista fue realizada con seguridad por maquinaria pesada, como atestigua la presencia de pequeñas arrastradas de estériles y escombros acumuladas en el lateral derecho de la vía durante su realización. Unos elementos que ni fueron nivelados ni explanados; no son, ni mucho menos, resaltes de gran entidad, pero generan bultos que en este caso se convierten en falsos positivos. Sin embargo, tras la prospección arqueológica en campo, no hay duda de que se trata del producto de una obra muy reciente, y por eso hubo que realizar un intenso filtrado de los círculos identificados y excluir aquellos acopios actuales, para poder discriminar los elementos prehistóricos de aquellos que no lo eran (fig. 11). Por otra parte, en Las Corradas se identificaron acertadamente los cuatro túmulos restantes (numerados de cuatro a siete), e incluso apareció un posible nuevo elemento, aunque no es seguro que esta nueva marca se corresponda con una estructura de naturaleza prehistórica. 


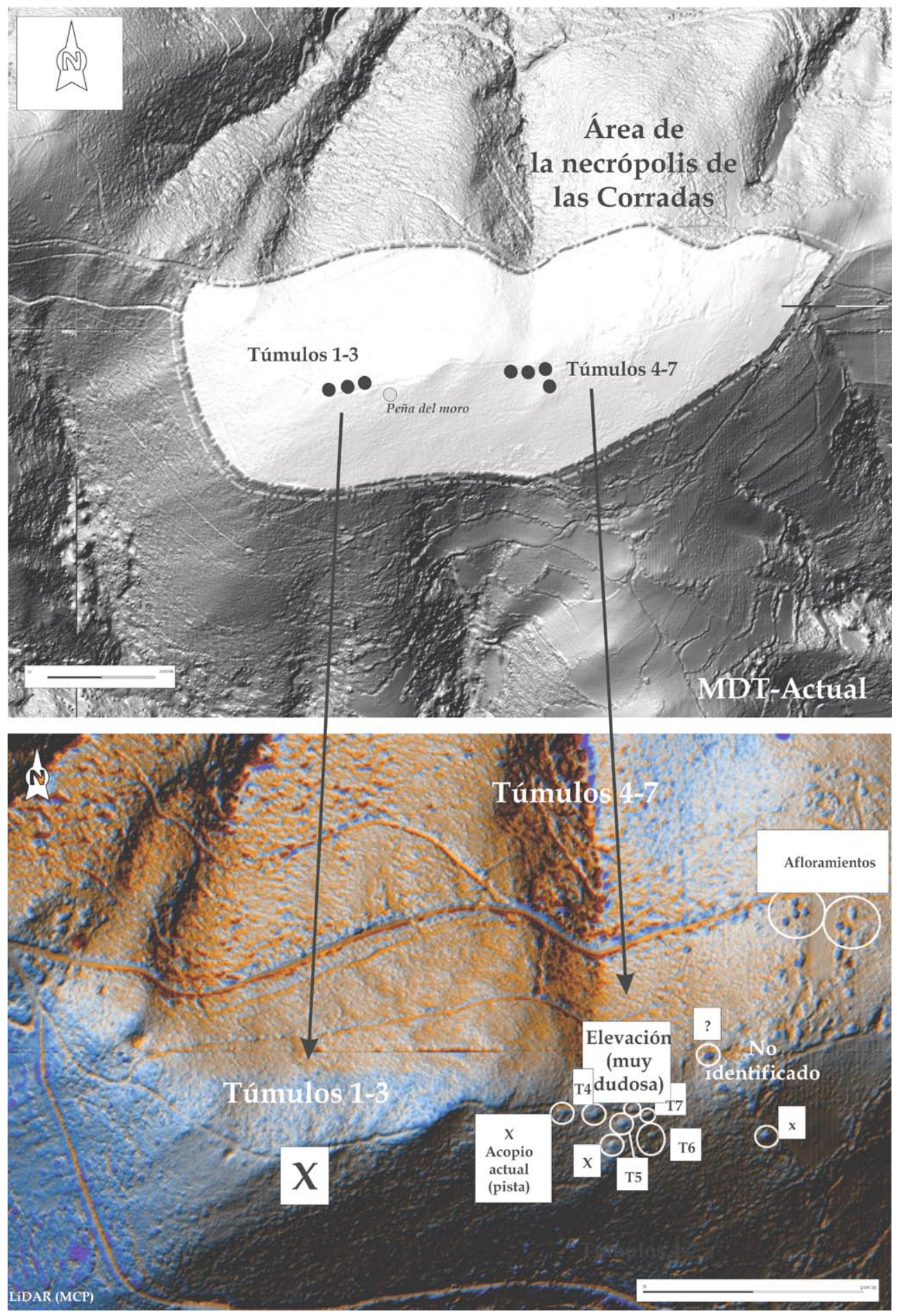

Figura 11. Necrópolis de las Corradas a) Distribución de las estructuras en el MDT utilizando los datos de la carta arqueológica; b) Imagen LiDAR con las localizaciones proporcionadas por esta herramienta. 


\section{Conclusiones: LÍNEAS de trabajo PRESEntes y Futuras}

El denominado Macizo Asturiano, que ocupa el tramo más occidental de la cordillera cantábrica y en el que se inscribe nuestro territorio de estudio, se caracteriza por un relieve intrincado, quebrado constantemente por sucesivas elevaciones que generan en muchos casos valles profundos, estimulando así un cierto aislamiento de las comunidades que poblaron, desde la Prehistoria, este territorio (Romero 1992, 2). Además, la evolución del espacio rural asturiano durante las últimas décadas nos ha conducido hacia un incremento de las masas forestales en las que el monte bajo crece sin ningún tipo de control (García 2016, 78). Las prospecciones remotas basadas en datos LiDAR resultan actualmente indispensables en territorios con las peculiaridades paisajísticas que acabamos de describir; mucho más cuando lo que se busca son evidencias de arquitecturas megalíticas. En este trabajo se resumen los primeros resultados obtenidos en cuatro necrópolis tumulares asturianas combinando esta herramienta con la prospección tradicional, para así renovar los datos del inventario de bienes neolíticos del concejo de Salas. Con la observación detallada de cada conjunto surgen, al margen de los trazos comunes a todo el megalitismo asturiano, múltiples peculiaridades. Principalmente porque no todos los espacios funerarios son exactamente iguales; al contrario, son un palimpsesto fruto de muchas acciones sobre el paisaje (sobre todo recientes) que, en ciertos casos, pueden confundir a las herramientas digitales. Mucho más en la peculiar arqueología regional, que exige al analista un buen conocimiento del territorio y de las evidencias arqueológicas que se pueden conservar. Siguiendo este argumento, la monumentalidad y los rasgos de nuestro megalitismo deben ser siempre entendidos, en primer lugar, en el marco territorial cantábrico. Solo en él se comprenden el menor alcance monumental de las arquitecturas primitivas, que distan mucho en rasgos de los logros constructivos de otras comunidades prehistóricas peninsulares, en los que el relieve no impuso condicionantes tan estrictos para el desarrollo de la vida o para la agrupación de las personas (De Blas 2013; Fábregas \& Vilaseco 2006, 4 y ss.; García \& Wheatley 2009; Linares 2018, 521).

Con el LiDAR se incrementó el nivel de información disponible para cada necrópolis, haciendo más sencilla o más rápida la identificación de estructuras, como nos ocurrió en los conjuntos salenses de San Juan, Idarga o las Corradas. Su uso permitió incluso añadir más datos en aquellos casos que, a pesar de enfrentarnos a abultamientos catalogados, no sabemos con seguridad si detrás de ellos hay una obra prehistórica o son más bien el resultado de catalogaciones erróneas recientes. Las nuevas herramientas y metodologías permiten también plantear estimaciones generales de las medidas o de los cubicajes de cada estructura, viejas preocupaciones en el estudio del megalitismo norteño (Eguileta 1999, 173). Los cálculos de volúmenes que estamos aplicando, sobre todo en la necrópolis de Penausén, facilitan construir propuestas partiendo de los vínculos existentes entre las tumbas y, quizás, sobre los ritmos en que estas se fueron erigiendo en cada zona.

Para que el ejercicio tenga además un interés metodológico se están comparando los datos obtenidos durante las prospecciones del terreno con los del LiDAR. Los trabajos de campo, en nuestro caso, ejercieron de compensación y de corrección de los barridos digitales, perfilando así un modelo de análisis que, en este paisaje tan específico, obtiene resultados positivos. Además, si nuestra intención es crear discursos históricos sobre estos grupos, estos no se pueden confeccionar únicamente desde la aplicación de técnicas novedosas, de modelos digitales del terreno o de la excavación individualizada de monumentos. El seccionamiento espacial de las actuales necrópolis, las visuales existentes, las posibles canteras o los vínculos del espacio funerario con el de los vivos, por poner objetos de estudio frecuentes, necesitan siempre de una amplia inversión en labores prospectoras con las que entender todas y cada una de esas variables dentro de un territorio. 
En definitiva, el proyecto de La Cobertoria está trabajando actualmente en este proceso de comprensión detallada y profunda del megalitismo del concejo de Salas. Debido al marco espacial que estamos cubriendo, y a que no podemos aislar las necrópolis de su entorno o de sus cementerios más próximos los resultados deben ser, forzosamente, parciales. En futuros trabajos nos fijaremos en ese derredor de los cementerios prehistóricos, que siempre será necesario considerar para lograr aproximaciones paisajísticas de mayor calado. De todas formas, los datos actuales ya permiten un análisis que, aunque no sea definitivo, es seguro y más claro; del mismo modo, y de cara a la conservación y conocimiento de estas tumbas prehistóricas, la labor de revisión y de geolocalización precisa siempre es un avance para afrontar su gestión futura. Aunque el fin último es y será siempre entender mejor las comunidades agrícolas neolíticas cantábricas, que humanizaron considerablemente los paisajes naturales gracias, entre otras cosas, a la construcción de estas tumbas imperecederas.

\section{Agradecimientos}

El Doctor Miguel Busto Zapico prestó su valiosa ayuda desinteresadamente en las prospecciones durante varias jornadas de campo en los trabajos de documentación de San Juan. Los estudiantes del grado de Historia Jesús Fernández López y Carlos García-Noriega Villa también formaron parte de los trabajos para el reconocimiento y estudio de algunas de estas necrópolis. Ambos colaboraron con el proyecto de La Cobertoria como parte del equipo de excavación del dolmen de La Cobertoria o como resultado de la Beca de Colaboración Santander-CRUE-Pyme que permitió becar durante tres meses a uno de los estudiantes.

\section{BibLIOGRAFÍA}

Bennett, R., K. Welham, R. A. Hill \& A. Ford, 2011, «Making the most of airborne remote sensing techniques for archaeological survey and interpretation», en: D. C. Cowley, Remote Sensing for Archaeological Heritage Management, Hungary: Archaeolingua, 99-107.

Bennett, R., K. Welham, R. Hill \& A. Ford, 2012, «Using LiDAR as part of a multi-sensor approach to archaeological survey and interpretation», en: R. Opitz, D. Cowley (eds.), Interpreting archaeological topography - airborne laser scanning, aerial photographs and ground observation, Oxford: Oxbow Books, $1-12$.

Bewley, R., S. Crutchley \& C. Shell, 2005, «New light on an ancient landscape: LiDAR survey in the Stonehenge World Heritage Site», Antiquity 79, 636-647.

Blas Cortina, M. Á. de, 1978, «El Cantón I y Penausen I: Noticias sobre las excavaciones de dos megalitos asturianos", Boletín del Instituto de Estudios Asturianos año n. ${ }^{\circ} 32$, n. ${ }^{\circ}$ 93-94, 323-333.

Blas Cortina, M. Á. de, 1980, «El megalito de Penausen I (Salas, Asturias)», Noticiario Arqueológico Hispánico 9, 65-90.

Blas Cortina, M. Á. de, 1983, La Prehistoria reciente en Asturias, [Estudios de Arqueología asturiana, n. ${ }^{\circ}$ 1], Oviedo: Fundación pública de cuevas y yacimientos prehistóricos de Asturias.

Blas Cortina, M. Á. de, 2006, «Túmulos prehistóricos en las Regueras: de su descubrimiento por José Manuel González a las excavaciones de los años ochenta», Estudios ofrecidos a José Manuel González en el centenario de su nacimiento, Las Regueras: La Piedriquina, 47-55.

Blas Cortina, M. Á. de, 2013, Terra et silva: una leve aproximación a los orígenes de la vida agropecuaria en la Asturias prehistórica, [Discurso leído por el autor en el acto de su solemne recepción académica el día 14 de marzo de 2013], Oviedo: Real Instituto de Estudios Asturianos. 
Bradley, R., 1991, «Rock art and the perception of landscape», Cambridge Archaeological Journal 1, 77-101.

Bradley, R., 1998, The significance of monuments. On the shaping of human experience in Neolithic and Bronze Age in Europe, London: Routledge.

Carrero Pazos, M., 2017, «El fenómeno tumular y megalítico en Galicia. Aportaciones desde los Sistemas de Información Geográfica y la estadística espacial para el estudio de los patrones de localización», [Tesis Doctoral, Universidade de Santiago de Compostela], http://hdl.handle.net/10347/15823

Carrero Pazos, M., A. Beva \& M. Lake, 2019, "The spatial structure of Galician megalithic landscapes (NW iberia): A case study from the Monte Penide region", Journal of Archaeological Science 108, August 2019, https://doi.org/10.1016/j.jas.2019.05.004.

Carrero Pazos, M., B. Vilas Estévez, E. Romaní Fariña \& A. Rodríguez Casal, 2014, "La necrópolis del Monte de Santa Mariña revisitada: aportaciones del LIDAR aéreo para la cartografía megalítica de Galicia», Gallaecia 33, 39-57.

Cerrillo Cuenca, E., \& P. Bueno Ramírez, 2019, «Counting with the invisible record? The role of LiDAR in the interpretation of megalithic landscapes in south-western Iberia (Extremadura, Alentejo and Beira Baixa)", Archaeological Prospection 26-3, 251-264.

Conrad, O., B. Bechtel, M. Bock, H. Dietrich, E. Fischer, L. Gerlitz, J. Wehberg, V. Wichmann \& J. Bohner, 2015, "System for Automated Geoscientific Analyses (SAGA) v. 6.2.0», Geosciences Modelling Development 8 (1991-2997), https://doi.org/10.5194/gmd-8-1991-2015

Eguileta Franco, J. M., 1999, A Baixa Limia galega na prehistoria recente: arqueoloxía dunha paisaxe da Galicia interior, Ourense: Deputación Provincial de Ourense.

Fábregas Valcarce, R., \& X. I. Vilaseco Vázquez, 2003, «El Neolítico y el Megalitismo en Galicia: problemas teórico-metodológicos y estado de la cuestión», en: V. S. Gonçalves, A. Catarina Sousa, A. Marqués de Faria, (coords.), Muita gente, poucas antas? Origens, espaços e contextos do megalitismo, Actas do II colóquio internacional sobre Megalitismo, Trabalhos de arqueologia 25, Lisboa: Instituto Portugués de Arqueología, 281-304.

Fábregas Valcarce, R., \& X. I. Vilaseco Vázquez, 2006, «En torno al megalitismo gallego», en: F. Carrera Ramírez, R. Fábregas Valcarce (coords.), Arte parietal megalitico en el noroeste peninsular: conocimiento y conservación, 11-36.

García Martínez, A., 2016, Alabanza de aldea, Oviedo: KRK Ediciones.

García Sanjuán, L., \& D. W. Wheatley, 2009, «El marco territorial de los dólmenes de Antequera: valoración preliminar de las primeras investigaciones», PH cuadernos, 23. Dólmenes de Antequera. Tutela y valorización hoy, Sevilla: Junta de Andalucía. Consejería de Cultura-Instituto andaluz de patrimonio histórico, 128-143.

GonZÁlez y Fernández-VallÉs, J. M., 1973, «Recuento de los túmulos sepulcrales megalíticos de Asturias", Archivum Tomo XXIII, 5-42.

IsenburG, M., 2014, LASTools - efficient LiDAR processing software (unlicensed), Obtained from http:// rapidlasso.com/LAStools.

Linares Catela, J. A., 2018, "Megalitismos del área de Huelva. Investigación y puesta en valor», en: J. C. de Senna Martinez, M. Diniz, A. F. de Cavalho (coords.), De Gibraltar aos Pirinéus. Megalitismo, vida e norte na fachada Atlántica peninsular, Fundação Lapa do Lobo, 519-539.

Martín de Cáceres, E., E. Cerrillo Cuenca \& A. Prada Gallardo, 2017, «Nuevas aportaciones al paisaje del Camino de la Plata a partir de tecnologías digitales de análisis del paisaje (LiDAR)», en: T. Nogales Basarrate, Lusitania. Del pasado al presente de la investigación. IX Mesa Redonda Internacional de Lusitania, Mérida: Museo Nacional de Arte Romano de Mérida, 313-340.

Martín Hernández, E., 2013, «Inventario arqueológico de Pesoz. Actualización», Excavaciones arqueológicas en Asturias 7 (2007-2012), Oviedo: Consejería de Educación, Cultura y Deporte-Mercantil Asturias, 537-541.

Martín Hernández, E., \& J. Camino Mayor, 2018, «Investigaciones arqueológicas en el cordal de la Carisa. Los campamentos de Llagüezos y la Cuaña Carraceo", Excavaciones arqueológicas en Asturias 8 (2013-2016), Oviedo: Consejería de Educación, Cultura y Deporte-Ediciones Trabe, 293-306. 
Martínez Cortizas, A., L. López Merino, R. Bindler, T. Mighall \& M. E. Kylander, 2016, «Early atmospheric metal pollution provides evidence for Calcolithic Bronze Age mining and metallurgy in Southwestern Europe», Science of the Total Environment 545-546, 398-406.

Menéndez Blanco, A., D. González Álvarez, V. Álvarez Martínez \& J. I. Jiménez Chaparro, 2013, "Campamentos romanos de campaña en el occidente de Asturias», Excavaciones Arqueológicas en Asturias 7 (2007-2012), Oviedo: Consejería de Educación, Cultura y Deporte-Mercantil Asturias, 245-251.

Montes López, R., 2013, "Revisión del inventario arqueológico de Tapia de Casariego", Excavaciones arqueológicas en Asturias 7 (2007-2012), Oviedo: Consejería de Educación, Cultura y Deporte-Mercantil Asturias, 543-547.

Orejas Saco Del Valle, A., F. J. Sánchez-Palencia Ramos \& J. A. Ron Tejedo, 2018, «Proyecto IVGA: conquista, dominación y explotación minera entre el conventus de los Astures y el Lucense», Excavaciones arqueológicas en Asturias 8 (2013-2016), Oviedo: Consejería de Educación, Cultura y Deporte-Ediciones Trabe, 239-252.

Rodríguez Del Cueto, F., \& M. A. De Blas Cortina, 2018, «Investigaciones iniciales en el megalito de La Cobertoria, en el paraje de la Campa San Juan (Mallecina, Salas)", Excavaciones Arqueológicas en Asturias 8 (2013-2016), Oviedo: Consejería de Educación, Cultura y Deporte-Mercantil Asturias, 171182.

Rodríguez del Cueto, F., \& M. Busto Zapico, 2020, «La construcción secular de un espacio funerario mediante distintas arquitecturas monumentales: primeras consideraciones tras las investigaciones realizadas en La Cobertoria (Salas, Asturias)», Lucentum XXXIX, 1-20. https://doi.org/10.14198/ LVCENTVM2020.39.xx

Rodríguez del Cueto, F., \& M. Carrero-Pazos, (ya aceptado; en prensa), «Using LiDAR as a tool for remote archaeological prospection: the prehistoric barrow landscapes of Penausen and Cobertoria (Salas, Asturias, Spain), CAA 2019 Krakow Proceedings.

Rodríguez Otero, V., 1990, "Carta arqueológica del concejo de Salas», Fichas del inventario disponibles en la Consejería de Cultura del Principado de Asturias.

Romero López, D., 1992, «El relieve de Asturias», Geografía de Asturias Tomo I, Oviedo: Editorial Prensa Asturiana, 1-16.

Sánchez Hidalgo, E., \& A. Menéndez Granda, 2009, «Actualización del inventario arqueológico de Gijón. Objetivos y resultados», Excavaciones arqueológicas en Asturias 6 (2003-2006), Oviedo: Consejería de Cultura y Turismo-Ediciones Trabe, 537-542.

Sánchez Hidalgo, E., \& A. MenÉndez Granda, 2013, «Trabajos en la necrópolis megalítico-tumular de Monte Areo (Carreño-Gijón). Identificación de estructuras, nuevos hallazgos, georreferenciación y señalización de las mismas», Excavaciones arqueológicas en Asturias 7 (2007-2012), Oviedo: Consejería de Educación, Cultura y Deporte-Mercantil Asturias, 389-393.

Santos Díaz-Nosty, B., 2004, Proyecto de actuación arqueológica para el parque eólico Sierra de Curiscao, Informe arqueológico inédito.

SuÁrez López, J., 2001, Tesoros, ayalgas y chalgueiros. La fiebre del oro en Asturias, Gijón: Fundación Municipal de Cultura, Educación y Universidad Popular. 